\title{
Working accuracy reliability analysis for open arc welders considering flexible deformations
}

\author{
Xing Han ${ }^{\mathrm{a}}$, Chang $\mathrm{Li}^{\mathrm{b}}$ \\ School of Mechanical Engineering \& Automation, University of Science and Technology Liaoning , \\ Anshan 114051, China \\ ahanxinggctx@163.com, ${ }^{b}$ lichang2323-23@163.com
}

Keywords: Reliability; Open arc welder; ADAMS; Random errors

Abstract. Open arc welders have been used widely nowadays. A welder's elastic deformation of every link would affect the final welding quality, and here it analyzed working accuracy reliability for open arc welder, taking flexible deformations into account, in this paper. Firstly, a parametric virtual model of the flexible welder was built by the ADAMS/View. Secondly, random errors were simulated by a program created from pseudo-random numbers, wrote by multiplicative congruence method. Lastly, Monte Carlo sampling calculation was implemented for the virtual model, and large sample data of the dynamic characteristics in welding process were obtained. These data was used to calculate the working reliability of the welding robot. This method included simplicity and high accuracy, and was highly promising for application in mechanism design.

\section{Introduction}

Randomness of engineering structures are: material characteristics randomness, geometry dimension randomness, boundary conditions randomness, and structure physical property randomness. Dynamic responses of a certain mechanism can vary with the working place, environment, and time of use even if the system itself does not change[1].

An open arc welder is composed of pinion-and-rack gear, screw-driven, guide rail sliding, and etc. Motion accuracy of the welding gun head is a key factor affecting the final welding quality. Therefore, to evaluate the effects of its flexible deformations on the mechanism working accuracy is very important. Traditionally, this flexible deformation was always neglected, once it was took into account, the results could be more accurate than before[2,3].

\section{Working reliability computing method for welder-considering flexible deformations}

Because of the random error generated in process of machining and installation, a welder's microscopic structure was random. Working reliability computing method for welder (considering flexible deform) was showed as Fig.1[4].

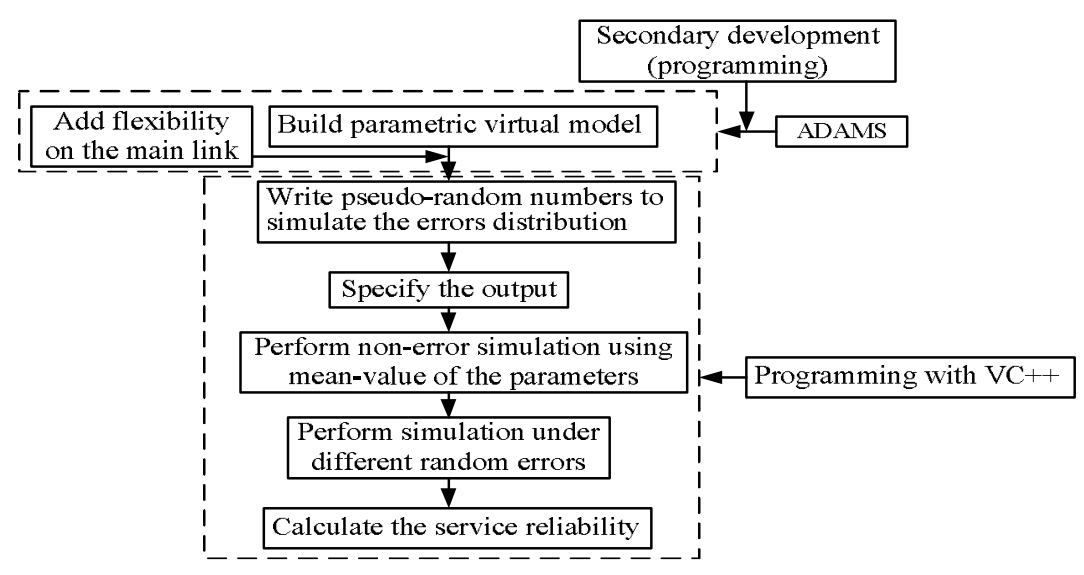

Fig.1 Working reliability computing flowchart 


\section{Simulation of the welder considering flexible deformations}

Modeling for the virtual welder test prototype The open-arc welder's inner structure was showed in Fig2, and its working process was:

1. Adjusted the gun head to prospective position;

2. When work piece began to rotate, the helical guide screw began clockwise rotating firstly, and the lateral arm moved $30 \mathrm{~mm}$ forward; the helical guide screw rotated counter clockwise secondly, and the lateral arm moved 30mm backward. In this way, the gun head was working as an alternate motion, and the amplitude of oscillation was $30 \mathrm{~mm}$.

3. After the piece rotated one circle, there was a weld bead, width was $30 \mathrm{~mm}$, generated on its surface.

4. Working as this circulation until to the whole piece surface was welded evenly.

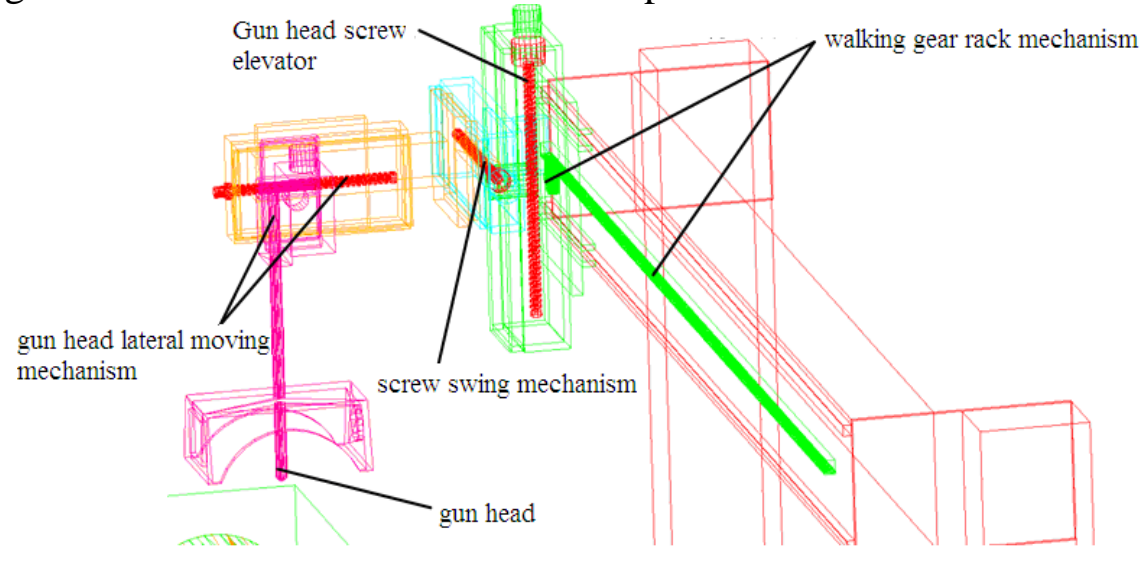

Fig.2 The open-arc welder's inner structure

Creating: according to the given dimensions, a virtual model of the welder was built in ADAMS/View module, and then created its flexible model in ADAMS $\backslash$ AutoFlex module, as showed in Fig.3. Restraints: kinematics pairs were applied on walking gear rack mechanism, gun head screw elevator, screw swing mechanism, gun head lateral moving mechanism, these kinematics pairs were gear pair, screw pairs, screw pairs, and sliding pairs separately.

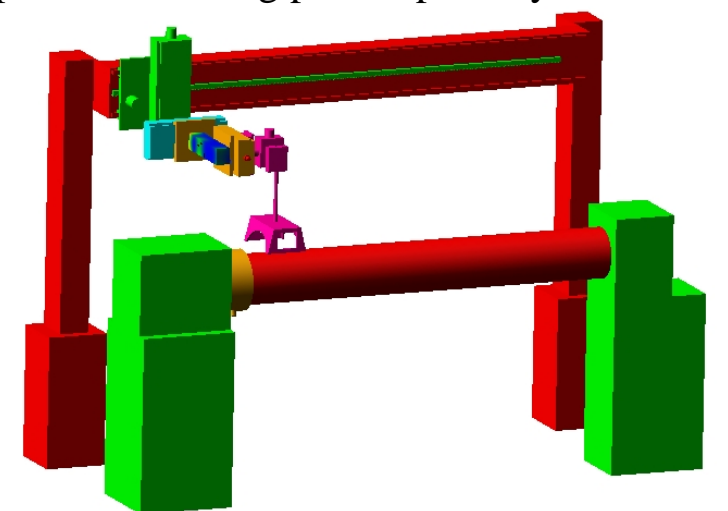

Fig.3 Welder flexible model

Simulation of the open arc welder considering flexible deformation. Use VC software to program the mechanism random errors, and then import ADMAS in this VC environment, start ADAMS simulation for this welder flexible virtual model. After the simulation, all of the results were obtained, such as displacement, speed, acceleration, and stress-strain. Here, it took the gun head as an example, its motion curves were showed in Fig.4[5,6]. 


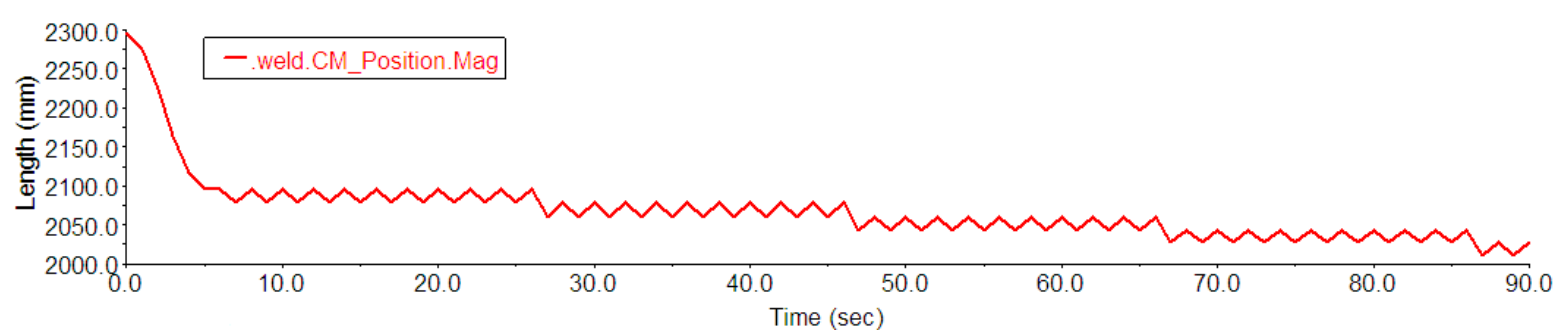

(a) Displacement curve of the gun head

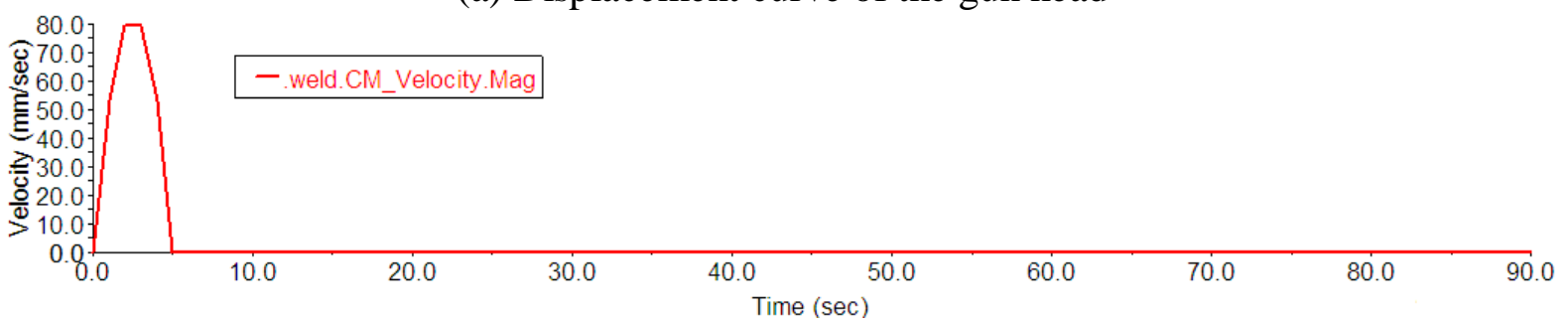

(b)Speed curve of the gun head

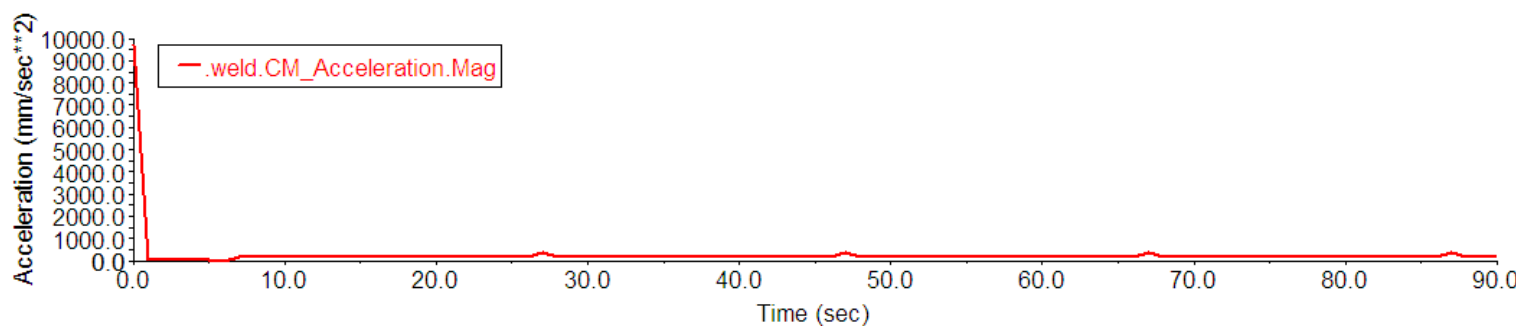

(c) Acceleration curve of the gun head

Fig.4 $(\mathrm{a} \sim \mathrm{c})$ Motion curves of the gun head

From the calculation, we learned that the gun head speed changed homogeneously, but when it moved near to the work piece, the acceleration reduced sharply and then stable towards. It pointed that the flexible model's deformation varied in a wide range, and was high non-liner. Comparing with the rigid model, the simulation considering flexible deformations approached to real values.

\section{Working reliability assessment of the welder considering flexible deformations}

A common analysis system of the welder working reliability was created using VC software and ADAMS, following the flow chart in Fig.1

With this service reliability analysis system, we could perform 30, 200, and 600 times simulations on the mechanism to calculate the Eigen-values for displacement limit error $(\mu 0, \sigma 0)=(0.15,0.05)$, allowable speed limit error $(\mu \mathrm{v} 0, \sigma \mathrm{v} 0)=(0.45,0.05)$, and allowable acceleration speed limit error $(\mu \mathrm{a} 0, \sigma \mathrm{a} 0)=(2,0.05)$. Using these values, the motion reliabilities of the mechanism end actuator can be calculated (Table.1).

Table 1 Working reliability of the welder

\begin{tabular}{|c|c|c|c|c|}
\hline \multicolumn{2}{|c|}{ Times $\quad$ Time } & $4 \mathrm{~s}$ & $20 \mathrm{~s}$ & $50 \mathrm{~s}$ \\
\hline 30 & $\begin{array}{c}\text { Speed } \\
\text { acceleration }\end{array}$ & $\begin{array}{l}0.963653 \\
0.994213\end{array}$ & $\begin{array}{l}0.963811 \\
0.997449\end{array}$ & $\begin{array}{c}0.961512 \\
0.99890\end{array}$ \\
\hline 200 & $\begin{array}{c}\text { Speed } \\
\text { acceleration }\end{array}$ & $\begin{array}{l}0.971812 \\
0.998078\end{array}$ & $\begin{array}{l}0.973154 \\
0.998154\end{array}$ & $\begin{array}{l}0.969634 \\
0.997442 \\
\end{array}$ \\
\hline 600 & $\begin{array}{c}\text { Speed } \\
\text { acceleration }\end{array}$ & $\begin{array}{l}0.973161 \\
0.998036\end{array}$ & $\begin{array}{c}0.973051 \\
0.9986266\end{array}$ & $\begin{array}{l}0.971234 \\
0.998689\end{array}$ \\
\hline
\end{tabular}




\section{Conclusions}

It proposed an effective method for the working reliability assessment for the welder when considering the affect of the main part's elastic deformation, and provided an analysis bases for the dynamic optimum design and reliability sensitively analysis.

It composed the advantages of the ADAMS software and VC software to consider the dependence between random errors, and it can improve the accuracy and efficiency of the mechanism design.

\section{Acknowledgements}

This work is financially supported by National Nature Science Foundation of China (E050402/51105187), Program for Liaoning Excellent Talents in University (013202), General program of Liaoning education department(L2014110), and Anshan youth scientific personnel foster $\operatorname{program}(0000077)$.

\section{References}

[1] An Weiguang, Cai Yinlin. Reliability analysis and optimistic design of the random mechanism system[M], Harbin: Publication of Harbin engineering university, 2005:1-2.

[2] Chang Li, Xing Han. Reliability virtual test of mechanism motion accuracy[J]. Journal of machine design, 2007,24(11):17-20.

[3] Weiguang An, Yinlin Cai. Reliability analysis and optimistic design of the random mechanism system[M], Harbin: Publication of Harbin engineering university, 2005,26(10):1175-1182.

[4] Tiejun Wang: Motion Reliability Simulation Based on ADAMS of A Serial-link Robot[D],Shenyang: Northeastern University, 2006. In Chinese.

[5] Chen Weiping, Zhang Yunqing, Ren Weiqun. Mechanism system dynamic analysis and ADAMS application course[M], Beijing: Publication of Tsinghua University,2005.

[6] Yi Wang, Liyan Wu, Liu Geng. Research of Modeling Flexible-rigid System Based on Mechanism. Journal of System Simulation, Vol.19 No.20, Oct.,2007,pp4708-4710 